\title{
Comparative Proteomic Analysis of the Response of Maize (Zea mays L.) Leaves to Long Photoperiod Condition
}

\author{
Liuji Wu ${ }^{1,2+}$, Lei Tian ${ }^{1,2+}$, Shunxi Wang 1,2, Jun Zhang ${ }^{3}$, Ping Liu ${ }^{1,2}$, Zhiqiang Tian ${ }^{1,2}$, \\ Huimin Zhang ${ }^{1,2}$, Haiping Liu $^{4}$ and Yanhui Chen ${ }^{1,2 *}$ \\ ${ }^{1}$ Henan Agricultural University and Synergetic Innovation Center of Henan Grain Crops, Zhengzhou, China, ${ }^{2}$ Key Laboratory \\ of Physiological Ecology and Genetic Improvement of Food Crops in Henan Province, Zhengzhou, China, ${ }^{3}$ Food Crops \\ Research Institute, Henan Academy of Agricultural Science, Zhengzhou, China, ${ }^{4}$ Department of Biological Science, Michigan \\ Technological University, Michigan, MI, USA
}

OPEN ACCESS

Edited by:

Hanjo A. Hellmann,

Washington State University, USA

Reviewed by:

Francisco Javier Medina,

Consejo Superior de Investigaciones Cientificas, Spain

Letizia Bernardo,

Università Cattolica del Sacro Cuore,

Italy

${ }^{*}$ Correspondence: Yanhui Chen

chy9890@163.com

${ }^{\dagger}$ These authors have contributed equally to this work.

Specialty section: This article was submitted to

Plant Proteomics,

a section of the journal

Frontiers in Plant Science

Received: 22 November 2015

Accepted: 17 May 2016

Published: 02 June 2016

Citation:

Wu L, Tian L, Wang S, Zhang J, Liu P,

Tian Z, Zhang H, Liu H and Chen Y

(2016) Comparative Proteomic

Analysis of the Response of Maize

(Zea mays L.) Leaves to Long

Photoperiod Condition.

Front. Plant Sci. 7:752.

doi: 10.3389/fpls.2016.00752
Maize (Zea mays L.), an important industrial material and food source, shows an astonishing environmental adaptation. A remarkable feature of its post-domestication adaptation from tropical to temperate environments is adaptation to a long photoperiod $(\mathrm{LP})$. Many photoperiod-related genes have been identified in previous transcriptomics analysis, but proteomics shows less evidence for this mechanism of photoperiod response. In this study, we sampled newly expanded leaves of maize at the three- and six-leaf stages from an LP-sensitive introgression line H496, the donor CML288, LP-insensitive inbred line, and recurrent parent Huangzao4 ( $\mathrm{HZ4}$ ) grown under long days (15 h light and $9 \mathrm{~h}$ dark). To characterize the proteomic changes in response to LP, the iTRAQ-labeling method was used to determine the proteome profiles of plants exposed to LP. A total of 943 proteins differentially expressed at the three- and six-leaf stages in $\mathrm{HZ} 4$ and H496 were identified. Functional analysis was performed by which the proteins were classified into stress defense, signal transduction, carbohydrate metabolism, protein metabolism, energy production, and transport functional groups using the WEGO online tool. The enriched gene ontology categories among the identified proteins were identified statistically with the Cytoscape plugin ClueGO + Cluepedia. Twenty Gene Ontology terms showed the highest significance, including those associated with protein processing in the endoplasmic reticulum, splicesome, ribosome, glyoxylate, dicarboxylate metabolism, L-malate dehydrogenase activity, and RNA transport. In addition, for subcellular location, all proteins showed significant enrichment of the mitochondrial outer membrane. The sugars producted by photosynthesis in plants are also a pivotal metabolic output in the circadian regulation. The results permit the prediction of several crucial proteins to photoperiod response and provide a foundation for further study of the influence of LP treatments on the circadian response in short-day plants.

Keywords: proteomic analysis, maize leaves, introgression line, iTRAQ, long photoperiod, cytoscape, circadian 


\section{INTRODUCTION}

Maize (Zea mays L.) is a key food source and industrial material that has rapidly spread in cultivation since originating in Southern Mexico 6000-10,000 years ago from Balsas teosinte (Zea mays ssp. parviglumis; Matsuoka et al., 2002). Balsas teosinte required short-day (SD) conditions for flowering (Emerson, 1924). One remarkable determinant enabling the spread of maize across latitudes was the post-domestication adaptation to changing in daylight hours (Piperno et al., 2009; van Heerwaarden et al., 2011). Under the longer days experienced at higher latitudes, tropical maize cultivars do not flower or show delayed flowering (Betran et al., 2003). Plants integrate signals from endogenous regulatory pathways or the environment to modulate the timing of flowering (Colasanti and Coneva, 2009). In the model plant Arabidopsis thaliana, numerous components associated with the plant circadian clock and photoperiod have been studied to understand the regulation and molecular mechanism of flowering in higher plant (Matsubara et al., 2008; Kumimoto et al., 2010; Lazakis et al., 2011; Knuesting et al., 2015). However, only a small number of genes such as ZCN1, ZCN8, and conzl identified by the Arabidopsis orthologues AtTFL1, AtFT, and AtCO, respectively (Danilevskaya et al., 2008; Matsubara et al., 2008; Miller et al., 2008; Lazakis et al., 2011), have been shown to be involved in the regulation of flowering time and the vegetative to reproductive transition in maize. Recently, numerous quantitative trait loci (QTLs) were affecting flowering date and response to photoperiod were detected, each with a small effect (Buckler et al., 2009). The photoperiod response may be influenced by only a small number of these floweringtime QTLs, including ZmCCT which encodes a CCT domaincontaining protein (Ducrocq et al., 2009; Coles et al., 2010; Hung et al., 2012). Previously, our research group identified CACTAlike transposable elements in ZmCCT, which were shown to attenuate the photoperiod sensitivity and to accelerate the postdomestication spread of maize (Yang L. T. et al., 2013).

The circadian system influences expression of a substantial fraction of the genes in a variety of species because of the diversity of clock outputs. Approximately 10 and $30 \%$ of genes are estimated to be regulated by the circadian system in mammals and plant, respectively (Panda et al., 2002; Michael and McClung, 2003; Covington et al., 2008). Circadian rhythms are entrained by environmental signals, such as temperature and light, and by endogenous sugar production by photosynthesis to enable a plant to adapt the local environment (Harmer et al., 2000; Haydon et al., 2013).

Recent studies on photoperiod response have highlighted the emergence of proteomic analysis as a promising tool. To our knowledge, our group is responsible for the only previous proteomic analysis of photoperiod responses in maize, using classical 2-D electrophoresis (2-DE) combined with mass spectrometry (MS; Wang et al., 2015). In that study, however, only a few proteins responsive to long photoperiod (LP) were identified (Wang et al., 2015). And in our study, we also used the bioinformatics tools WEGO (GO annotation) and Cytoscape (v3.0.2) plugin ClueGO + Cluepedia v2.1 (GO-KEGG network) for functional classification and enrichment analysis, and argue that photoperiod response to LP will show a close relationship with protein synthesis, metabolism process, post-transcriptional regulation and mitochondrial outer membrane. None of this is included in the Wang et al. (2015) article. For each functional category, we identified more proteins compared with the Wang et al. (2015) study. Especially for these "circadian" related proteins. Therefore, the current study lays a foundation for future elucidation of the protein network regulatory mechanism underlying the photoperiod response.

Stevia rebaudiana plants grown under long-photoperiod (LP) conditions show increased leaf size, internode length and dry weight, but reduced intervals between successive leaf pairs, compared with plants grown under SD (Metivier, 1979). However, few studies on proteomic fluctuations in response to LP in the maize leaf have been undertaken. To clarify the mechanism involved in alterations of the proteome, in the present study we collected newly expanded third and sixth leaves from the photoperiod-insensitive maize inbred line Huangzao4 (HZ4) and the photoperiod -sensitive inbred line H496 obtained through crossing the recurrent parent of HZ4 with CML288 (non-recurrent parent). A total of 5259 proteins and 14 proteins directly related to the photoperiod were identified by isobaric tags for relative and absolute quantitation (iTRAQ) labeling in response to the LP condition.

\section{MATERIALS AND METHODS}

\section{Plant Materials}

The near-isogenic lines H496, which is highly photoperiodsensitive, was derived from a cross between HZ4 (the recurrent parent) and a tropical maize inbred line, CML288, The latter was acquired from the National Maize and Wheat Improvement Center in Mexico, whereas HZ4 is a representative of the Chinese Tangsipingtou heterotic group. Four plants were grown in each $15 \mathrm{~cm}$ pots under LP conditions (15/9 h, light/dark; $\mathrm{Ku}$ et al., 2011). Newly developed third and sixth leaves were collected for proteomic analysis. All leaf samples were immediately frozen in liquid nitrogen stored at $-80^{\circ} \mathrm{C}$ until use.

\section{Sucrose and Glucose Measurement}

Fresh leaf material of HZ4 and H496 sampled at three- and six-leaf stages (15/9 h, light/dark) were separately ground to fine powder with a mortar and pestle in liquid nitrogen. The sucrose and glucose content was determined by enzyme-coupled reactions using the Sucrose/D-Glucose/D-Fructose assay kit (RBiopharm, Darmstadt, Germany) as described by Thalor et al. (2012). A sample (200 $\mathrm{mg}$ ) of the powder was immediately boiled with $600 \mu \mathrm{l}$ distilled water for $15 \mathrm{~min}$ in a water bath. After centrifugation $\left(16,000 \times \mathrm{g}, 15 \mathrm{~min}\right.$ at $\left.4^{\circ} \mathrm{C}\right), 100 \mu \mathrm{l}$ of the supernatant was used for absorbance determination in the sucrose assay by the spectrophotometer (Hitachi U-2900, Hitachi, Tokyo, Japan).

\section{Fe Content Measurement}

Leaves at the three- and six-leaf stages of the two maize inbreds were collected in three biological replications for $\mathrm{Fe}$ concentration analyses. One hundred microgram of the leaves 
were dried for $2-3$ days at $70^{\circ} \mathrm{C}$, then digested with $1 \mathrm{ml}$ of $13 \mathrm{M}$ $\mathrm{HNO} 3$ and $1 \mathrm{ml}$ of $8.8 \mathrm{M} \mathrm{H} 2 \mathrm{O} 2$ (Wako, Japan) at $220^{\circ} \mathrm{C}$ for 20 min using MARS Xpress oven (CEM, USA) as described by Masuda et al. (2008); After digestion, the samples were diluted to $5 \mathrm{ml}$ and analyzed using a SPS1200VR ICPAES (Seiko, Japan).

\section{Protein Digestion and iTRAQ Labeling}

Digestion of protein was carried out in accordance with the filteraided sample preparation (FASP) protocol used by Wisniewski et al. (2009). Briefly, the method used was as follows. For each sample, $200 \mu \mathrm{g}$ proteins were suspended in $30 \mu \mathrm{l}$ STD buffer (4\% SDS, $150 \mathrm{mM}$ Tris- $\mathrm{HCl}, 100 \mathrm{mM}$ DTT, pH 8.0), incubated in boiling water for $5 \mathrm{~min}$ and then cooled to room temperature. The DTT (detergent) and other low-molecularweight components were diluted with $200 \mu$ l UA buffer $(150 \mathrm{mM}$ Tris- $\mathrm{HCl}, 8 \mathrm{M}$ urea, $\mathrm{pH} 8.0$ ) and transferred by repeated ultrafiltration (Microcon units, $30 \mathrm{kD}$ ). Next, $100 \mu \mathrm{l}$ of 0.05 mol.L-1 iodoacetamide (IAA) was added to the UA buffer to block the reduced cysteine residues. The mixture was incubated in darkness for $20 \mathrm{~min}$. The filters were washed three times with $100 \mu \mathrm{l}$ UA buffer and then twice with $100 \mu$ l DS buffer (50 mM triethylammonium bicarbonate, $\mathrm{pH}$ 8.5). Finally, $2 \mu \mathrm{g}$ trypsin (Promega, Madison, USA) was used to digest the protein suspensions in $40 \mu \mathrm{l} \mathrm{DS}$ buffer at $37^{\circ} \mathrm{C}$ overnight. The digested peptides were collected as a filtrate. The concentration of peptides was measured by UV light spectral density at $280 \mathrm{~nm}$ using an extinction coefficient of 1.1 of $0.1 \%(\mathrm{~g} / \mathrm{l})$ solution, which was calculated based on the frequency of tyrosine and tryptophan in vertebrate proteins.

For labeling, the digested products of the peptide mixture were labeled with 8plex iTRAQ ${ }^{\circledR}$ Reagents following the manufacturer's instructions (Applied Biosystems). Briefly, $70 \mu \mathrm{l}$ of ethanol was used to dissolve each iTRAQ reagent and then the solution was combined with respective peptide mixture. The samples were labeled (496-6Y)-113, (496-3Y)-114, (HZ4-6Y)115 , and (HZ4-3Y)-116 and were multiplexed and vacuum-dried.

\section{Peptide Fractionation with Strong Cation Exchange (SCX) Chromatography}

An AKTA purifier system (GE Healthcare) was used to fractionate iTRAQ-labeled peptides. Reconstitution and acidification of the dried peptide mixture were performed using $2 \mathrm{ml}$ of buffer A [ $10 \mathrm{mM} \mathrm{KH} 2 \mathrm{PO} 4$ in 25\% (v/v) acetonitrile, $\mathrm{pH}$ 2.7]. The products were loaded onto a polysulfethyl $4.6 \times 100 \mathrm{~mm}$ column ( $5 \mu \mathrm{m}, 200 \AA$ A; PolyLC Inc., Columbia, MD, USA). A gradient of $0-10 \%$ buffer $\mathrm{B}[10 \mathrm{mM} \mathrm{KH} 2 \mathrm{PO} 4$ in $25 \%(\mathrm{v} / \mathrm{v})$ acetonitrile, $500 \mathrm{mM} \mathrm{KCl}, \mathrm{pH}$ 2.7] was used for elution of the peptides at a flow rate of $1 \mathrm{ml} \mathrm{min-1}$ for $2 \mathrm{~min}, 10-20 \%$ buffer $\mathrm{B}$ for $25 \mathrm{~min}, 20-45 \%$ buffer B for $5 \mathrm{~min}$, and $50-100 \%$ buffer B for $5 \mathrm{~min}$. The elution was monitored by absorbance at $214 \mathrm{~nm}$, and fractions were collected at 1-min intervals. All collected fractions ( $\sim 30)$ were finally grouped into 10 pools and desalted on C18 cartridges [Empore ${ }^{\mathrm{TM}}$ SPE cartridges C18 (standard density), bed i.d. $7 \mathrm{~mm}$, volume $3 \mathrm{ml}$, Sigma]. After concentration by vacuum centrifugation, each fraction was reconstituted in $40 \mu \mathrm{l}$ of $0.1 \%$ $(\mathrm{v} / \mathrm{v})$ trifluoroacetic acid. Before liquid chromatography-tandem mass spectrometry (LC-MS/MS) analysis, all samples should be stored at $-80^{\circ} \mathrm{C}$.

\section{LC-ESI MS/MS Analysis}

Q Exactive EM $^{\mathrm{TM}}$ mass spectrometer coupled with an EasynLC chromatography system (Proxeon Biosystems, now Thermo Fisher Scientific) were used to perform the following experiments. For nano LC-MS/MS analysis, totally $10 \mu \mathrm{l}$ of each fraction was used. The peptide mixture $(5 \mu \mathrm{g})$ was loaded into the $\mathrm{C} 18$ reversed-phase column $(15 \mathrm{~cm}$ length, $75 \mu \mathrm{m}$ id) packed in-house with RP-C18 $5 \mu \mathrm{m}$ resin in buffer $\mathrm{A}(0.1 \%$ formic acid) and separated by buffer $\mathrm{B}$ with a linear gradient $(0.1 \%$ formic acid and $80 \%$ acetonitrile $)$ at the flow rate of 250 $\mathrm{nl} / \mathrm{min}$ controlled by an Intelli Flow Technology controller over $140 \mathrm{~min}$. Data-dependent top 10 method, which dynamically chose the most abundant precursor ions from the survey scan $(300-1800 \mathrm{~m} / \mathrm{z})$ for HCD fragmentation, was used to acquire the MS data. Predictive automatic gain control (pAGC) was applied to determinate the target value. Dynamic exclusion duration was $60 \mathrm{~s}$. Resolution for survey scans was set to 70,000 at $\mathrm{m} / \mathrm{z}$ 200, while for HCD spectra, the resolution 17,500 at $\mathrm{m} / \mathrm{z} 200$. $30 \mathrm{eV}$ was applied for normalized collision energy and $0.1 \%$ was defined for the underfill ratio which specifies the minimum percentage of the target value likely to be reached at maximum fill time. Peptide recognition mode was enabled during the running of the instrument.

\section{Sequence Database Search and Data Analysis}

MASCOT engine (Matrix Science, London, UK; version 2.2) was embedded into the Proteome Discoverer 1.3 (Thermo Electron, San Jose, CA, USA) for searching MS/MS spectra against the decoy database and UniProt Plant database $(134,648$ sequences, downloaded on May 5, 2013). The following parameters were used for identifying proteins. $\pm 20 \mathrm{ppm}$ is set for peptide mass tolerance, $0.1 \mathrm{Da}$ for MS/MS tolerance, 2 for missed cleavage, enzyme is trypsin, fixed modification: carbamidomethyl (C), iTRAQ4/4plex(K), iTRAQ4/4plex(Nterm), Variable modification: oxidation (M), iTRAQ4plex (Y), $20 \mathrm{ppm}$ for integration window tolerance, 0 for minimum quan value threshold, 2 for fold change threshold for up/down regulation, 100 for maximum allowed fold change, and FDR is no more than 0.05 (Sandberg et al., 2012). For iTRAQ studies, we used confidence scores $>1.2$-fold, FDR $\geq 0.05$, as the qualification criterion, which corresponded to a peptide confidence level of 95\% (Yang Q. et al., 2013).

\section{Bioinformatics}

As described by Ye et al. (2006), Gene Ontology (http://www. geneontology.org/) and WEGO (http://wego.genomics.org.cn/) online tools were used for functional analysis of the proteins. The statistically enriched gene ontology (GO) categories for the identified protein interactome were determined by Cytoscape (v3.0.2) plugin ClueGO + Cluepedia v2.1.3 (Bindea et al., 2009, 2013). The analysis was carried out using the proteins identified in the three-leaf and six-leaf stage in these two inbred lines. Biological processes, subcellular locations, molecular function 
and KEGG (Kyoto Encyclopedia of Genes and Genomes) pathways (Kanehisa and Goto, 2000), which were inferred electronic annotation and experimental data, were all in the identified GO categories. A minimum level of 5 and a maximum level of 11 were set as the GO level interval with a minimum of two genes per category. And a right-sided hypergeometric test for enrichment analysis was elicited applying against the ClueGO $Z$. Mays reference genome.

\section{Post-hoc Test}

To verify the main variable contributing to the differences, a twoway analysis of variance with post-hoc test was performed using SAS software (SAS Institute Inc., Cary, NC, USA).

\section{RESULTS AND DISCUSSION \\ Phenotypes and Growth Parameters between HZ4 and H496 in Maize}

To examine the protein changes response to the photoperiod in maize leaves, plant phenotypes were periodically observed in the two inbred lines HZ4 and H496 under LP at the three- and sixleaf stages, and the individual samples were collected. Under the LP condition, plants of the H496 line were considerably taller than those of the HZ4 line. HZ4 plants showed less photoperiod sensitivity than $\mathrm{H} 496$ plants, in which flowering was delayed by 1 week (Table 1). The two lines showed similar leaf and shoot apex phenotypes at each of the three- and six-leaf stages (Figure 1).

Previously, the number of leaves and morphologies of the shoot apical meristem were used to indicate the inductive phase changes of photoperiod sensitivity in maize. This showed that the juvenile vegetative stage was completed between the fourand five-leaf stages in HZ4 and CML288 under LP condition (Wu et al., 2008). In the present study, we observed that the shoot apical meristem was elongated in the six-leaf stage in both HZ4 and H496 inbred lines (Figures 1E-H), which proved that plants were in different developmental phases at the three- and six-leaf stages. Thus, it seems that examination of photoperiodsensitive phenotypic traits is significant during improvement of maize germplasm.

\section{ITRAQ Analysis of Protein Expression in Response to LP Condition}

In this study, 23,767 unique peptides were analyzed. A total of 5259 proteins were identified by MS/MS (Table S 1). The peptides of the identified proteins are listed in Tables S 1, S 2. According to the criteria for recognition of differentially expressed proteins (fold change ratio $>1.2$ and $p<0.05$ ), 943 proteins differentially expressed between H496 and HZ4 were

TABLE 1 | Phenotypes of the maize inbred line HZ4 and near-isogenic line H496 grown under long-photoperiod conditions.

\begin{tabular}{llll}
\hline Name & Plant Height & Tasseling stage & Silking \\
\hline HZ4 & 127 & $60(0.30)$ & $70(0.32)$ \\
H496 & 164 & $67(0.48)$ & $79(0.26)$
\end{tabular}

identified, of which 185 proteins were differentially expressed at both developmental stages (Table S 3), 398 proteins showed differential expression at the three-leaf stage (Table S 4), and 360 proteins were only differentially expressed at the six-leaf stage (Figure 2A, Table S 5). The results showed that the difference between the inbred lines lead to the changes of the proteins. Of the differentially expressed proteins, 278 upregulated and 305 downregulated proteins were identified at the three-leaf
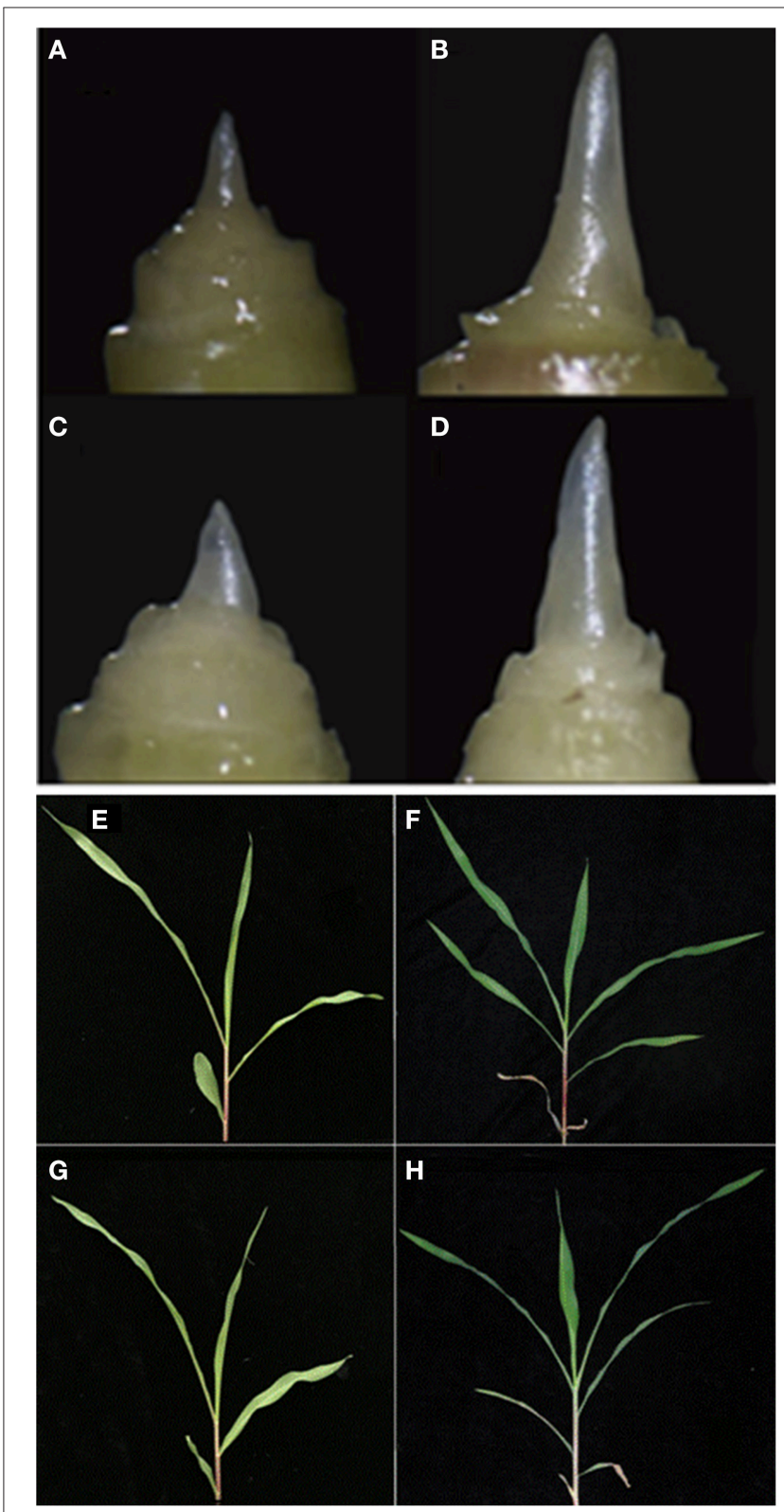

FIGURE 1 | Morphology of the shoot apex and leaves at the three- and six-leaf stages of maize inbred line $\mathrm{HZ4}$ and $\mathrm{H} 496$ grown under long-photoperiod conditions. (A-D) Shoot apex of $\mathrm{HZ} 4$ at the three-leaf stage (A) and six-leaf stage (B). Shoot apex of $\mathrm{H} 496$ at the three-leaf stage (C) and six-leaf stage (D). (E-H) Leaves of HZ4 at the three-leaf stage (E), and six-leaf stage (F); shoot apex of $\mathrm{H} 496$ at three-leaf stage (G), and six-leaf stage $\mathbf{( H )}$. 

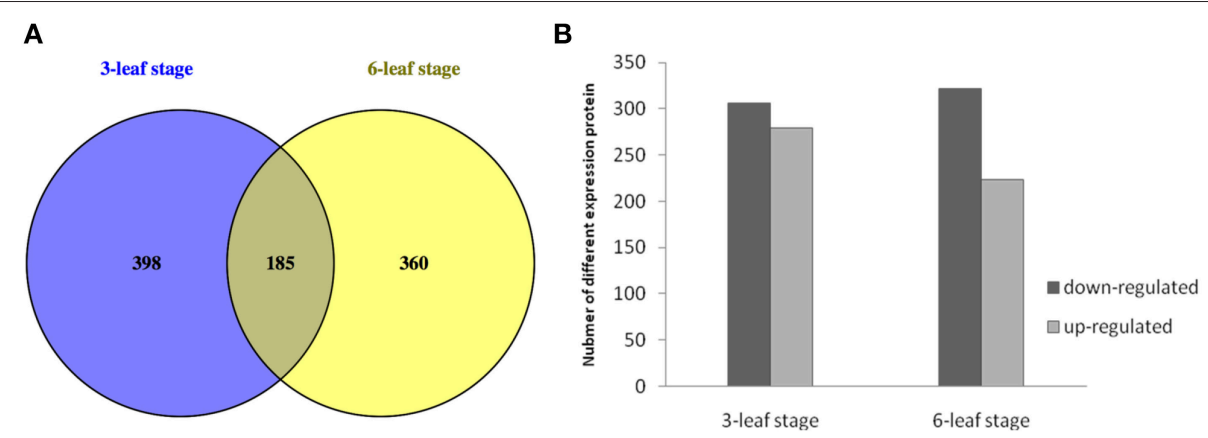

FIGURE 2 | Expression patterns between HZ4 and $\mathrm{H496}$ at the three- and six-leaf stage grown under long-photoperiod conditions. (A) Venn diagram of differentially expressed proteins identified in $\mathrm{HZ} 4$ and $\mathrm{H} 496$ at the three- and six-leaf stages. (B) Number of differentially expressed proteins identified in $\mathrm{HZ} 4$ and $\mathrm{H} 496$ at three- and six-leaf stages.

stage (Figure 2B, Tables S 3, S4), and 223 upregulated and 322 downregulated proteins were detected at the six-leaf stage (Figure 2B, Tables S 3, S5).

Analysis of variance confirmed that there were significant differences in protein expression between the inbred lines, but there was no significant difference between the two developmental stages (Table S 6). Previously, our group used the H496-10 line which was produced after one less generation of back-crossing with HZ4 than $\mathrm{H} 496$ via gel-based proteomic approach to provide novel insights into the influences of longphotoperiod treatments on short-day plants (Wang et al., 2015), but there are significant differences and considerable novelty in this study, we choosed three- and six-leaf stage as two distinct phases in order to verify what proteins change in expression before and after the onset of the induction phase according to Wu et al. (2008). And 943 proteins differentially expressed were identified, while only 22 differentially expressed proteins between HZ4 and H496-10 (Wang et al., 2015). Clearly, this current report by iTRAQ method identified many additional proteins and presents further evidence with which to understand the photoperiod response in maize.

\section{Functional Characterization of Protein Interaction Network}

We analyzed the GO annotation of the 943 proteins that were expressed differentially at the three- and six-leaf stages of H496 compared with HZ4 (Tables S 3-S 5) to gain insights into the functions of the proteins and the mechanism involved in the photoperiod pathway. The WEGO tool was used to plot the distribution of GO annotations (Figure 3). The differentially expressed proteins were grouped into three hierarchically structured GO terms, namely biological process, cellular component, and molecular function. The differentially identified proteins were subcategorized into 16 main hierarchically structured GO classifications including 4 biological processes, 10 cellular components, and 2 molecular functions (Figure 3). Specifically, "metabolic process" and "cellular process" were highly represented in "biological process"; "cell part", "cell" and "intracellular" were incorporated in "cellular component"; and "binding," "catalytic activity" were represented in "molecular function" (Figure 3). This analysis indicated that the identified proteins involved in these GO categories may play the most important roles in regulation of the photoperiod response to LP.

Based on molecular functions, biological processes and KEGG pathways (Kanehisa and Goto, 2000), we also generated a GO annotation and KEGG network (KEGG-GO; Reference Genome Group of the Gene Ontology 2009) using the Cytoscape plugin Cluego + Cluepedia (Bindea et al., 2009, 2013). Twenty terms were connected by 38 edges with the kappa scores, and showed considerable enrichment $(p<0.05)$ in the identified protein interactome (Figure 4). The most significant terms comprised those associated with protein processing in endoplasmic reticulum, splicesome, ribosome, glyoxylate, dicarboxylate metabolism, L-malate dehydrogenase activity, and RNA transport (Figure 5A). With regard to subcellular location, all proteins showed significant enrichment in the mitochondrial outer membrane (Figure 5B).

\section{Protein Synthesis}

Protein turnover, which represents the balance between protein synthesis and degradation, is one of the many forms of regulation that is employed to achieve a unified cellular response (Reinbothe et al., 2010). In the present study, the most significant function enrichment pathway terms were ribosome, protein processing in endoplasmic reticulum, and RNA transport, which are involved in protein synthesis (Figure 5A). Missra et al. (2015) calculated the rate of protein synthesis by multiplying transcript abundance by translation state in Arabidopsis to show that high translation rates of TOC1 and LUX mRNAs at night may allow many related proteins to continue to repress transcription of the morning genes CCA1 and LHY, and of day genes such as GI and PRR9, which argued that it is plausible that differences in the waveform of protein synthesis rates may help to fine-tune circadian gene function (Missra et al., 2015). Recently, it has been reported that DNA replication during the cell cycle causes protein synthesis rates to show sharp, periodic jumps that can entrain the circadian clock in the cyanobacterium Synechococcus elongates (Paijmans et al., 2016). The present results provide additional evidence that protein synthesis has an important role in circadian regulations. 


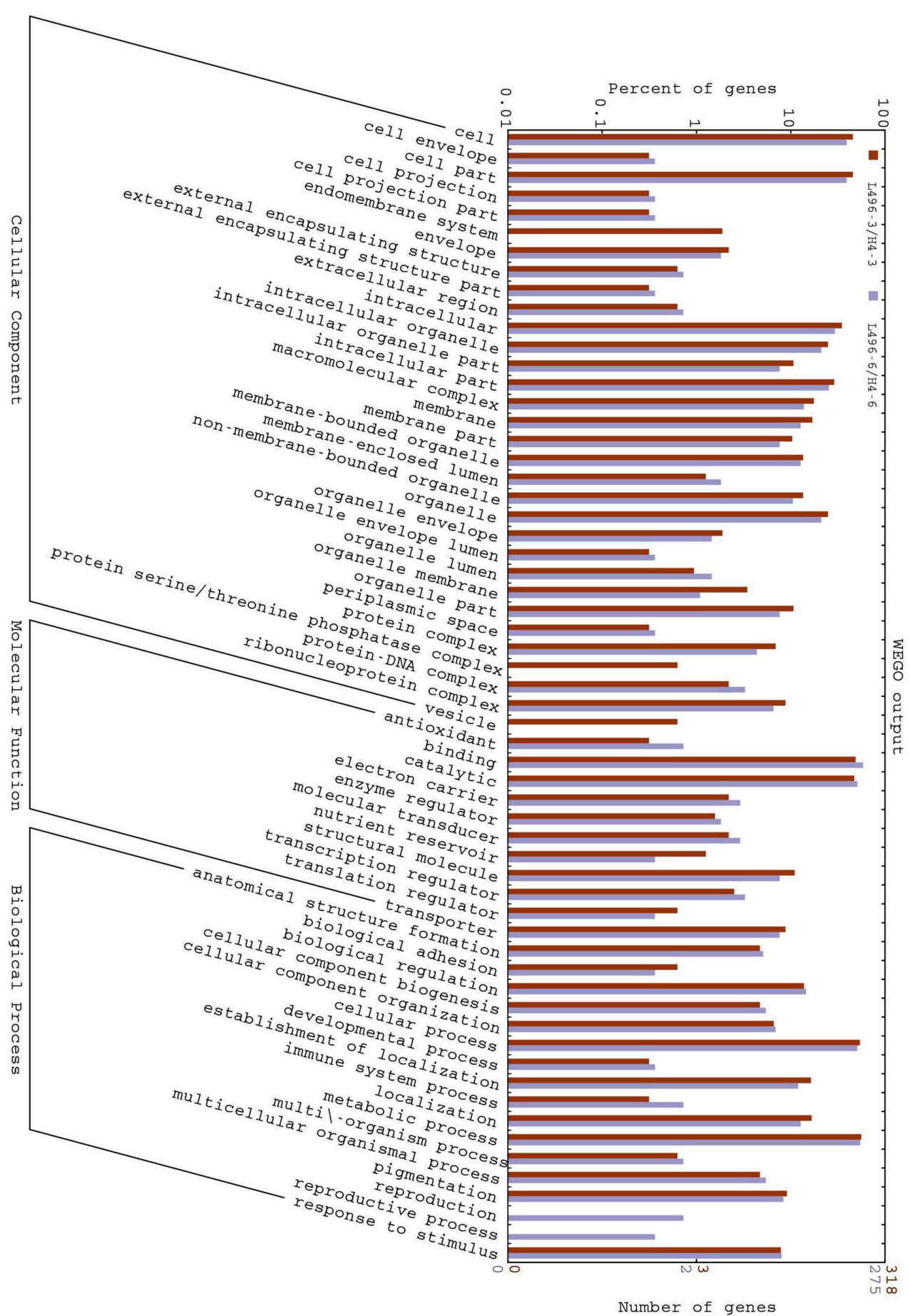

FIGURE 3 | Gene Ontology (GO) classification of differentially expressed proteins at the three- and six-leaf stages identified by iTRAQ-labeling experiments between $\mathrm{HZ4}$ and $\mathrm{H}$ 496. The differentially expressed proteins are grouped into three hierarchically structured GO terms: biological process, cellular component, and molecular function. The $y$-axis indicates the number and percent of proteins in each GO term.

\section{Metabolism Process}

As Figure 3 shown, Metabolism process constituted a high percentage $(>70 \%)$ of the GO terms and Glyoxylate and dicarboxylate metabolism also elucidated significant enrichment in the KEGG-GO network (Figures 5A,B). These results indicated that amino acid metabolism may show distinct differences between HZ4 and H496 in response to LP. Connections between circadian clocks and carbon metabolism 


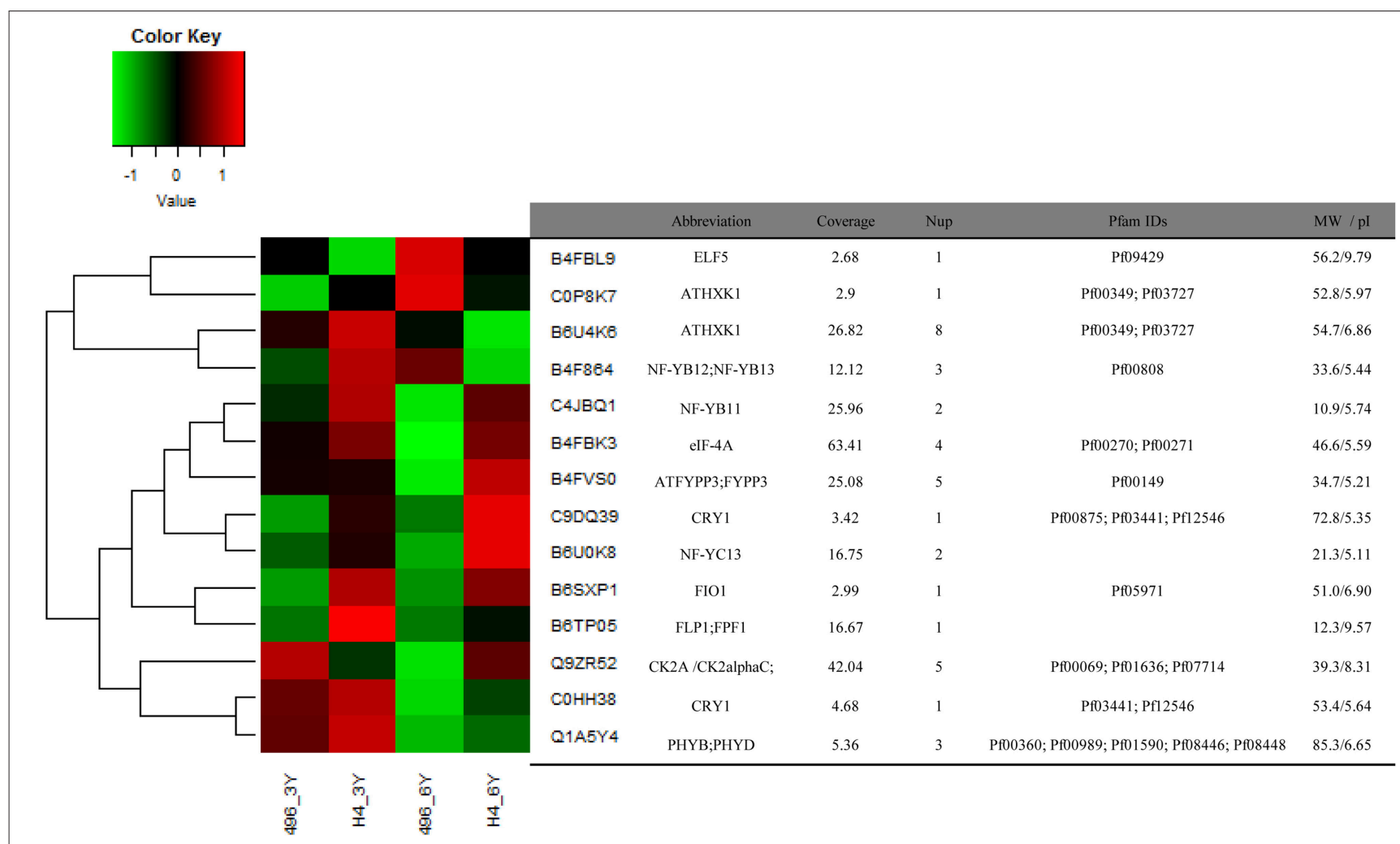

FIGURE 4 | Expression patterns of 14 identified proteins associated with light and photoperiod response in maize Huangzao4 (HZ4) and H496 grown under long-photoperiod conditions. The heatmap was plotted using log2 values and scaled from a change of - 1 to 1 log2 change.

has been reported previously by Müller et al. (2014), and recently quantitative circadian phosphoproteomic analysis of Arabidopsis has revealed extensive clock control of key components in physiological, metabolic and signaling pathways and these findings showed new interaction networks that confer previously uncharacterized rhythms onto metabolism and physiology (Choudhary et al., 2015).

\section{Post-Transcriptional Regulation}

In 2011, Staiger D. and Köste T. have reviewed that posttranscriptional control in the circadian system of modern organisms, Drosophila, mammals, Neurospora, Chlamydomonas and Arabidopsis (Staiger and Köster, 2011). Notably, the next year alternative splicing (AS), as one type of post-transcriptional regulation, was reported as a way of linking the circadian clock to temperature response in Arabidopsis by AS of circadian gene CCA1(Park et al., 2012). Recently, Papasaikas and collaborators observed that GEMIN2, the only component of the SMN complex that is conserved from yeast to humans, controls the pace of the circadian clock under standard growth conditions in Arabidopsis by controlling the AS of TOC1 and other core clock genes (Papasaikas et al., 2015).

\section{Mitochondrial Outer Membrane}

In a study of the mitochondrial outer membrane in Arabidopsis, Duncan et al. (2011) developed a statistically rigorous quantitative proteomic workflow to confidently determine components of the outer mitochondrial membrane proteome of Arabidopsis. The proteins identified range from plantspecific proteins with unknown functions to proteins that have putative functions in mitochondrial signaling, morphology, and defense responses. In the present study, the mitochondrial outer membrane, as the only significantly enriched subcellular location, may be an important and novel location for proteins associated with photoperiod response (Figure 5B).

\section{Protein Species Expressed Specifically Related to Photosynthesis in Three-Leaf Stage or Six-Leaf Stage in Response to LP between $\mathrm{HZ4}$ and $\mathrm{H} 496$}

Under LP condition, some differentially expressed proteins identified in H496 compared with HZ4 exhibited similar proteome patterns at both the three- and six-leaf developmental stages (Figure 2A)., Such proteins included the Gibberellin receptor GID1L2 (B6TKC8), pollen-specific protein (B6TIS3), cryptochrome 2 (C9DQ39), and cyptochrome P450 super family protein (B4FQH2) (Table S 3). The majority of proteins identified in the two inbred lines differed between the threeleaf and six-leaf stages (Figure 2A, Tables S 4, S 5). In addition, photoperiod altered the expression of all differentially expressed proteins involved in carbon and energy metabolism, including 
A

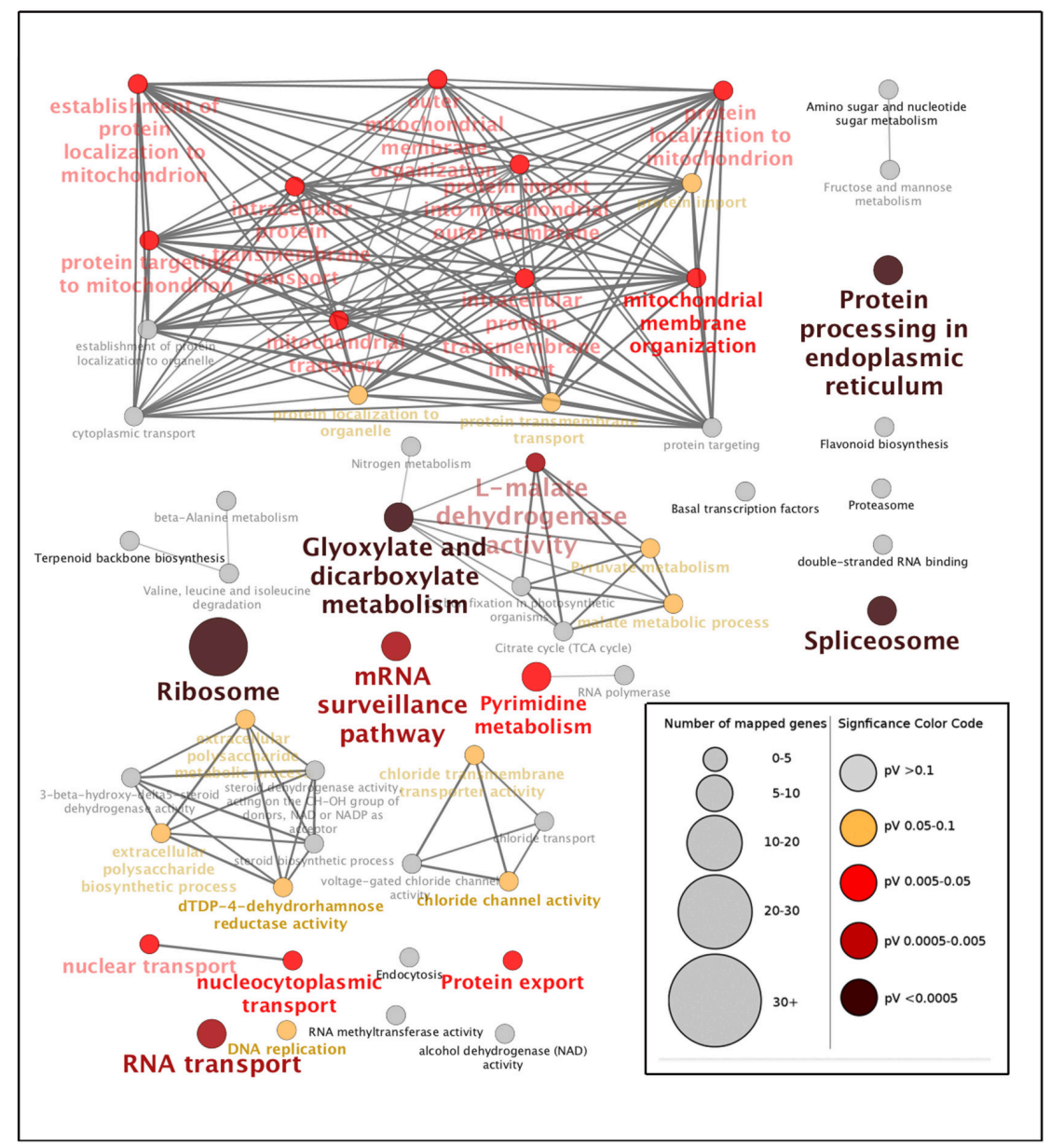

B

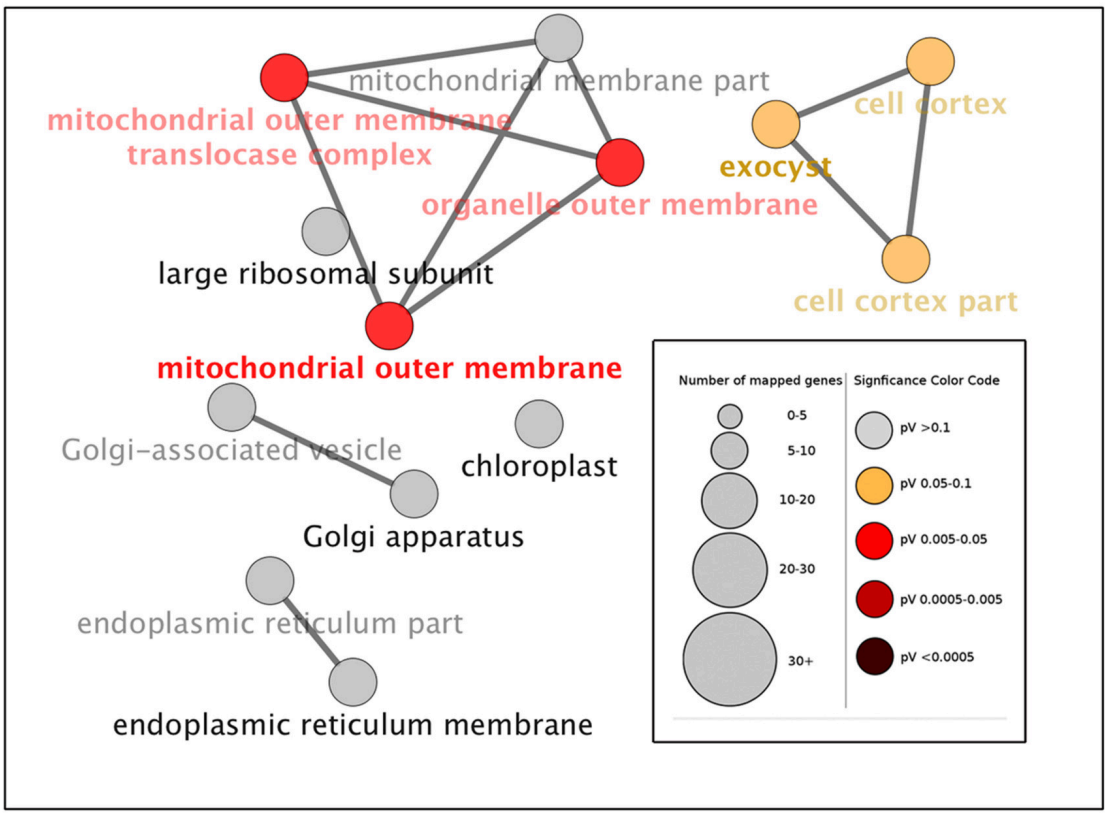

FIGURE 5 | Gene Ontology (GO) enrichment analysis of identified proteins at the three- and six-leaf stages of maize Huangzao4 (HZ4) and H496 grown under long-photoperiod conditions. Different expressions of the protein interactome at the three- and six-leaf stages of $\mathrm{HZ} 4$ and $\mathrm{H} 496$ was analyzed using the 
FIGURE 5 | Continued

Cytoscape plug-in ClueGo + Cluepedia to identify statistically enriched GO categories compared with the ClueGO maize reference genome. (A) GO categories searched include biological processes, molecular function, KEGG pathways, and (B) cell component. Nodes represent a specific GO term and are grouped based on the similarity of their associated proteins. Each node represents a single $\mathrm{GO}$ term and is color-coded based on enrichment significance ( $\mathrm{pV}=p$-value). Node size indicates the number of proteins mapped to each term. Edge thickness represents the calculated kappa score based on the number of proteins shared between terms. Functional groups are labeled by the most significant term in the group. Arrow indicates positive regulation.

ribosome, L-malate dehydrogenase activity, glyoxylate and dicarboxylate metabolism (Figure 5A). Some specially expressed proteins play a specific role in photosynthesis at both the threeand six-leaf stages (Figure 2A, Tables 2, 3). The three main classes were carbohydrates, amino acids, and lipids (Tables 2, 3), the protein amounts of these three metabolites (34/56, 60.7\%) were higher in H496 compared with HZ4 at the three-leaf stage; but at the six-leaf stage only half of these proteins showed elevated expression. This result indicated that photosynthesis at the two developmental stages of HZ4 and H496 may show different regulatory mechanism responses to the LP condition.

\section{Carbohydrate}

The proteins involved in carbon assimilation showed significant changes in abundance under LP. A previous report indicated that enzymes functioning during the reduction phased of the Calvin-Benson cycle accumulated to higher levels shoot tips under LP, whereas the level of enzymes involved in carboxylation and regeneration phases was increased in shoot tips under SD condition (Victor et al., 2010). In the present study, triose phosphate isomerase (B6AMV7), an important enzyme in the Calvin-Benson cycle, was less abundant in LP leaves (Table 3). This result contradicts previous observations and may be owing to differences between tissues, or the mechanisms of the response to LP in leaf may be more complex and involve additional regulators than compared with that in the shoot tips.

Potentially increased availability of carbohydrate under LP may be the reason for elevated accumulation of enzymes responsible for glycolysis, such as malate dehydrogenase (B4FZU8, B4FG53, B4FRJ1, F6MFD6; Table 3), which are involved in the pathway following glycolysis and were also more abundant in leaves. In Arabidopsis, the activities of enzymes involved in the glycolysis pathway were decreased in response to a shortened photoperiod, whereas activity of enzymes participating in photosynthesis and starch synthesis remained high.

As a diurnally regulated carbohydrate, sucrose content increases during light conditions and decreases during dark conditions, consistent with previously reports for other plants, such as potato (Urbanczyk-Wochniak et al., 2005). Glucose6-phosphate, which is responsible for sucrose biosynthesis as well as degradation, exhibited a similar pattern to that of sucrose (Urbanczyk-Wochniak et al., 2005). Hoffman et al. (2010) reported that diurnal fluctuations were regulated by several Krebs-cycle intermediates in pool sizes. In our study, we measured the sucrose and glucose contents in the leaf of HZ4 and H496 at the three- and six- leaf stages. The sucrose and glucose contents in H496 were slightly lower than those of HZ4 at the three-leaf stage, but higher at the six-leaf stage (Figures S 1A, B). This finding indicated that sucrose and glucose showed homeostatic changes in response to LP in the development of the two lines. Malate dehydrogenase showed an activated pattern at the three-leaf stage in H496, with an increased level compared to HZ4. Significant differences also observed for several proteins involved the metabolites between the two species at both stages (Tables 2,3). These results provide new evidence to further verify carbohydrate will mediated the circadian response.

\section{Chloroplast Proteins}

Adequate light harvesting for photosynthesis is closely related with the abundance of chloroplast proteins, such as chlorophyll $\mathrm{a} / \mathrm{b}$ binding protein, which is responsible for energy transfer in the reactive center in photosystem II (Kovács et al., 2006). This protein is responsible for balancing the distribution of excitation energy between photosystems: I and II (Kovács et al., 2006). Interestingly, one of these genes encoding chloroplast a/b binding protein was homologous to known genes that are responsible for the floral transition or morphology and the circadian rhythm photoperiod response in maize, rice and Arabidopsis (Coles et al., 2010). In the present study, expression of two chlorophyll $a / b$ binding proteins, K7TWD9 and B4FV94, was increased in H496. Thus, these two proteins are predicted to be involved in the circadian rhythm response, but confirmation requires further investigation.

\section{Ribosomal Proteins}

We detected 27 ribosomal proteins, of which 16 proteins were upregulated and 11 proteins were downregulated (Tables 2, 3). Previously, the ribosomal protein gene L34 (rpL34), which encodes a cytoplasmic ribosomal protein with high homology to the rat 605 r-protein, was isolated from a genomic library of tobacco (Nicotiana tabacum cv. Xanthi-nc), and histochemical GUS staining showed that rpL34 promoter activity was high in actively growing tissues, including various meristems, floral organs and developing fruits (Dai et al., 1996). In the present study, the ribosomal protein L34 was downregulated in HZ4 only at the six-leaf stage, which is the stage at which shoot apex morphology changes (Wu et al., 2008). Thus, the early flowering habit of HZ4 may be caused by activation of the ribosomal protein. Conversely, translation, especially the production of ribosomal proteins, is positively correlated with the abundance of phosphorylated S6 protein (Williams et al., 2003; Turck et al., 2004). The phosphorylation of L29-1, a 60S ribosomal protein, is enhanced under moderate "day time," and the possibility of diurnal regulation of translation in plants is indicated by differential phosphorylation of at least three ribosomal proteins: the 40S ribosomal proteins S6-1 and S6-2, and the 60S ribosomal protein L29-1 (Turkina et al., 2011). 
TABLE 2 | Functional classification of identified proteins significantly differentially expressed at the three-leaf stage of maize HZ4 and H496 plants exposed to long-photoperiod conditions.

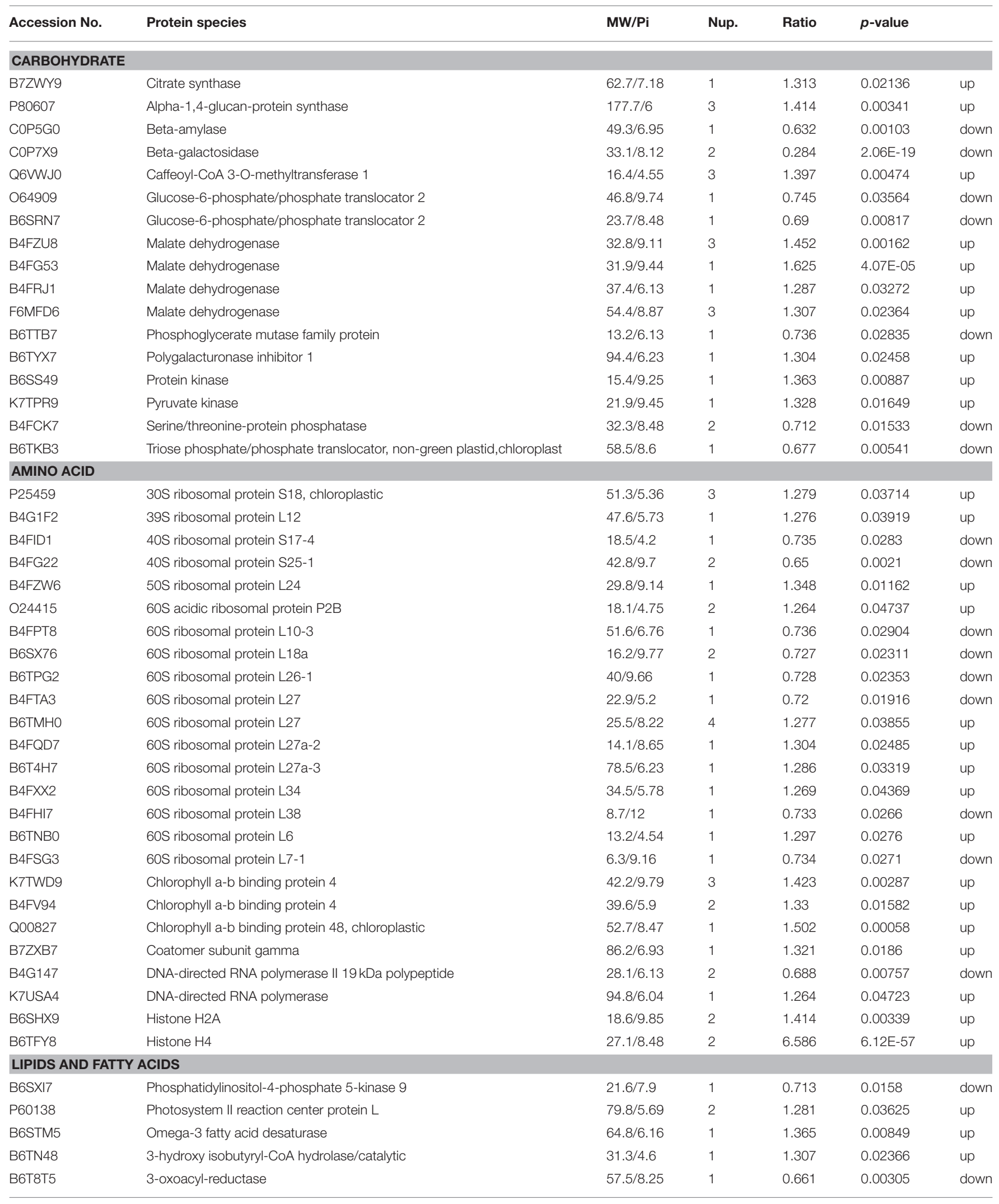


TABLE 2 | Continued

\begin{tabular}{|c|c|c|c|c|c|c|}
\hline Accession No. & Protein species & MW/Pi & Nup. & Ratio & $p$-value & \\
\hline B4FFE7 & Acyl carrier protein & 8/12.02 & 1 & 1.376 & 0.0069 & up \\
\hline B6U6S2 & Acyl-CoA synthetase long-chain family member 3 & $8 / 4.59$ & 3 & 1.471 & 0.00111 & up \\
\hline B6UEF8 & ATP binding protein & $37.9 / 8.27$ & 2 & 0.757 & 0.04689 & down \\
\hline K7VCM2 & Putative RING zinc finger domain superfamily protein & $7.2 / 4.35$ & 1 & 1.532 & 0.00031 & up \\
\hline K7TPR9 & Pyruvate kinase & $21.9 / 9.45$ & 1 & 1.328 & 0.01649 & up \\
\hline О82579 & Ribosomal protein L26 (Fragment) & $71.6 / 5.6$ & 2 & 0.682 & 0.00633 & down \\
\hline \multicolumn{7}{|l|}{ PHOTOPERIOD } \\
\hline Q6WWJ0 & Caffeoyl-CoA 3-O-methyltransferase 1 & $16.4 / 4.55$ & 3 & 1.397 & 0.00474 & up \\
\hline Q8LK10 & DNA methyltransferase DMT106 & $18.1 / 8.94$ & 1 & 0.125 & $6.13 \mathrm{E}-50$ & down \\
\hline О82579 & Ribosomal protein L26 (Fragment) & $71.6 / 5.6$ & 2 & 0.682 & 0.00633 & down \\
\hline
\end{tabular}

Annotations were obtained from the UniProtKB/Swiss-Prot databases (http://www.expasy.org/).

In the current study, a higher number of ribosomal proteins were upregulated in H496, and the 60S ribosomal protein L29 showed a higher expression level in H496, which is consistent with the above-mentioned report (Turkina et al., 2011). However, information on the exact mechanisms to explain increased protein production in the light phase of the photoperiod is extremely limited. The present findings shed some light on this conundrum by indicating that a portion of the enhanced protein synthesis may result from diurnal regulation of translation by complex combinatorial phosphorylation of ribosomal proteins. Overall, whether the ribosomal proteins are upregulated or downregulated, it would be an important cue in the regulation of flowering and photoperiod response, but the molecular function and regulatory mechanism for each ribosomal protein are poorly known and require further investigation in the future.

\section{Expression Pattern of Iron Metabolism-Related Proteins under LP Condition}

Anti-oxidative molecules, such as ferritin, are essential to detoxify reactive oxygen species or buffer irons to prevent oxidative stress (Ravet et al., 2009). Iron is a critical component for the function of many photosynthetic proteins, and iron deficiency causes an extended free-running period of rhythm changes and increases the production of reactive oxygen species (Salome et al., 2013). Thus, a higher level of ferritin 1 may correspond to enhanced detoxifying process of reactive oxygen species and distinct reactions to LP treatments. In the present research, the increase in accumulation of ferritin 1 (K7U2L3) of inbred line H496 leaves at six-leaf stage was higher than that in HZ4 under LP (Figure S1 C), suggesting that the strength of photosynthesis and the production of photosynthetic protein were higher in H496 compared with HZ4.

\section{Expression Pattern of Circadian-Associated Proteins under LP Condition}

Sorts of categories of circadian-associated proteins have been identified, and the expression patterns of 14 circadian associated proteins were examined (Figure 4). We found that eight proteins were upregulated in HZ4 in three-leaf stage, and five in sixleaf stage. But compared with that in H496, many proteins were elevated in HZ4 of three-leaf $(11 / 14,78.57 \%)$ and sixleaf stage $(9 / 14,64.28 \%)$, except that Q9ZR52 (CK2 alpha) were downregulated at the three-leaf stage, as well as C0P8K7 (AtHXK1), B6U4K6 (AtHXK1) and B4F864 (NF-YB12; NFYB13) in the six-leaf stage. Interestingly, the amount of B4FBL9 (ELF5) decreased at both stages while B4FVS0 (ATFYPP3) and Q1A5Y4 (PHYB; PHYD) have no change separately in three-leaf and six-leaf stage.

Post-translational regulation of CONSTANS (CO) protein is another key element of the photoperiodic induction of FLOWERING LOCUS T (FT) transcription (Möglich et al., 2010). Phytochrome is an important regulator coordinating downstream signaling components, and many studies have focused on elucidating novel components involved in light signal transduction (Paul and Khurana, 2008). The combination of CO with NF-Y transcription factors activates FT during floral initiation, which is dependent on photoperiod (Kumimoto et al., 2010). An ELF5 (B4FBL9) mutation, elf5, partially suppresses the photoperiod pathway and causes early flowering under SD, suggesting that ELF5 controls flowering independent of FLOWERING LOCUS C (FLC), a floral repressor upon which many of the flowering pathways converge (Noh et al., 2004). Moreover, ELF4 regulates the access of GIGANTEA (GI) to chromatin by sequestering GI from the nucleoplasm into subnuclear bodies preferentially during the night, thus restricting its ability to bind to the $C O$ promoter (Kim et al., 2013). Recently, the FPF1 (B6TP05) class genes have been explored, which may act as a regulator of flowering and the formation of wood in poplar (Hoenicka et al., 2012). To attain synchrony with day and night, the clock is entrained via the red/far-red-absorbing PHYTOCHROMES (PHYA-PHYE), the blue light-absorbing CRYPTOCHROMES (CRY1 and CRY2), and the LOV (LIGHT, OXYGEN, VOLTAGE) domain proteins ZEITLUPE (ZTL), FLAVIN BINDING, KELCH REPEAT, F-BOX1 (FKF1), and LOV KELCH PROTEIN 2 (LKP2) (Devlin, 2002; Fankhauser and Staiger, 2002) (Figure 6). 
TABLE 3 | Functional classification of identified proteins significantly differentially expressed at the six-leaf stage in maize HZ4 and H496 plants exposed to long-photoperiod conditions.

\begin{tabular}{|c|c|c|c|c|c|c|}
\hline Accession No. & Protein species & MW/pl & Nup. & Ratio & $p$-Value & \\
\hline \multicolumn{7}{|c|}{ CARBOHYDRATE } \\
\hline Q9SBJ3 & 6-phosphogluconate dehydrogenase isoenzyme A & $19 / 5.07$ & 1 & 1.32 & 0.0466823 & up \\
\hline COPIW1 & Glucose-6-phosphate 1-dehydrogenase & $68.3 / 8.82$ & 3 & 1.623 & 0.000531937 & up \\
\hline B4FAK9 & Glyceraldehyde-3-phosphate dehydrogenase, cytosolic & $43.3 / 8.27$ & 3 & 1.317 & 0.048407 & up \\
\hline B6TZ09 & Limonoid UDP-glucosyltransferase & $51.9 / 4.88$ & 1 & 1.781 & 3.64E-05 & up \\
\hline P49081 & Malate synthase, glyoxysomal & $61.6 / 6.64$ & 1 & 0.594 & 0.00275703 & down \\
\hline K7UJM1 & Putative O-Glycosyl hydrolase superfamily protein & $32.9 / 5.74$ & 1 & 0.637 & 0.00973655 & down \\
\hline B6TV55 & Stem 28 kDa glycoprotein & $32.1 / 9.13$ & 1 & 0.397 & 1.13E-07 & down \\
\hline B6SMV7 & Triosephosphate isomerase & $25 / 7.9$ & 1 & 0.527 & 0.00023741 & down \\
\hline B6TY47 & UDP-glucuronic acid decarboxylase 1 & $45.3 / 9.41$ & 1 & 0.595 & 0.0029176 & down \\
\hline \multicolumn{7}{|l|}{ AMINO ACIDS } \\
\hline B4FQ29 & 26S proteasome non-ATPase regulatory subunit 13 & $43.8 / 5.69$ & 3 & 0.665 & 0.0192674 & down \\
\hline P06586 & 30S ribosomal protein S3, chloroplastic & 25.9/9.74 & 8 & 1.386 & 0.0195563 & up \\
\hline B6T1J3 & 40S ribosomal protein $\mathrm{S} 13$ & 16.9/10.45 & 1 & 1.326 & 0.0433027 & up \\
\hline B6TJ93 & $40 S$ ribosomal protein S15a & $14.7 / 9.82$ & 2 & 1.356 & 0.0290148 & up \\
\hline B6TM74 & $50 S$ ribosomal protein $\mathrm{L} 27$ & 19.6/10.36 & 2 & 1.329 & 0.0417262 & up \\
\hline K7UI47 & $50 S$ ribosomal protein L35 & 8/11.4 & 2 & 1.316 & 0.0489937 & up \\
\hline P46252 & $60 S$ acidic ribosomal protein $\mathrm{P} 2 \mathrm{~A}$ & $11.4 / 4.28$ & 1 & 0.621 & 0.00624524 & down \\
\hline $\mathrm{B} 6 \mathrm{SPH} 4$ & 60S ribosomal protein L29 & $6.9 / 10.68$ & 1 & 1.502 & 0.00360954 & up \\
\hline В6Т098 & 60S ribosomal protein L34 & $13.7 / 11.49$ & 1 & 0.633 & 0.0087787 & down \\
\hline B6SX73 & $60 S$ ribosomal protein L35 & $14.3 / 11.28$ & 3 & 1.395 & 0.0172634 & up \\
\hline B6SIY6 & $60 S$ ribosomal protein $L 44$ & $12.1 / 10.2$ & 3 & 1.324 & 0.0443997 & up \\
\hline COPI96 & DNA-directed RNA polymerase & 40.6/9.09 & 2 & 0.54 & 0.000402232 & down \\
\hline B4G237 & Histone H2A & $14 / 10.05$ & 2 & 0.403 & $1.82 \mathrm{E}-07$ & down \\
\hline B4FYZ0 & Histone H2B & 16.1/10.05 & 1 & 1.434 & 0.00987423 & up \\
\hline B6T1G5 & Histone H2B & $16 / 10.08$ & 1 & 1.352 & 0.0308925 & up \\
\hline P49120 & Histone H2B.4 & $15.2 / 10.02$ & 1 & 0.669 & 0.0210391 & down \\
\hline \multicolumn{7}{|c|}{ LIPIDS AND FATTY ACIDS } \\
\hline B4FJG4 & DNA-directed RNA polymerase II 8.2 kDa polypeptide & $8.3 / 5.06$ & 1 & 0.556 & 0.000755199 & down \\
\hline B6U6C1 & Flavonol synthase/flavanone 3-hydroxylase & $44.8 / 5.02$ & 1 & 0.487 & 3.70E-05 & down \\
\hline COPIW1 & Glucose-6-phosphate 1-dehydrogenase & $68.3 / 8.82$ & 3 & 1.623 & 0.000531937 & up \\
\hline B4FAK9 & Glyceraldehyde-3-phosphate dehydrogenase, cytosolic & 43.3/8.27 & 3 & 1.317 & 0.048407 & up \\
\hline B7ZZX9 & Lipoxygenase & $98.1 / 6.71$ & 6 & 1.761 & 5.15E-05 & up \\
\hline B6TCR8 & Protein binding protein & $34.6 / 4.13$ & 3 & 0.532 & 0.000287393 & down \\
\hline B6U0J9 & Protein binding protein & $71.9 / 4.97$ & 3 & 0.632 & 0.00835835 & down \\
\hline B4FWN6 & Putative RING zinc finger domain superfamily protein & $36.1 / 7.77$ & 1 & 0.668 & 0.0205105 & down \\
\hline \multicolumn{7}{|l|}{ PHOTOPERIOD } \\
\hline P06586 & 30S ribosomal protein S3, chloroplastic & 25.9/9.74 & 8 & 1.386 & 0.0195563 & up \\
\hline K7URS7 & Putative cytochrome P450 superfamily protein & $64.2 / 7.97$ & 4 & 0.68 & 0.0271578 & down \\
\hline
\end{tabular}

Annotations were obtained from the UniProtKB/Swiss-Prot databases (http://www.expasy.org/).

Some additional proteins related to plant circadian rhythms have been identified. overexpression of Arabidopsis hexokinases (AtHXK1, C0P8K7, and B6U4K6) in tomato plants may reduce photosynthesis, inhibit growth and accelerate senescence (Dai et al., 1999), These results indicate that the activity of endogenous hexokinase is not a factor limiting growth rate, but functions to regulate photosynthesis in photosynthetic tissues. Overexpression of AtHXK1 in tomato plants also reduced the chlorophyll content. From this result, we assume that HXK, as a sugar phosphorylation enzyme, is a negative regulator of photosynthesis. The study by Miao et al. (2013) reinforces and extends the argument that the promoted biosynthesis of aliphatic glucosinolate by glucose is involved in HXK1and/or RGS1-mediated signaling through the transcription factors MYB29, MYB28 and ABI5. In a previous study we demonstrated that in transgenic Arabidopsis plants, ZmHd6, encoding a protein similar to the Arabidopsis of CASEIN KINASE2 alpha subunit (CK2 alpha, Q9ZR52), affected the 


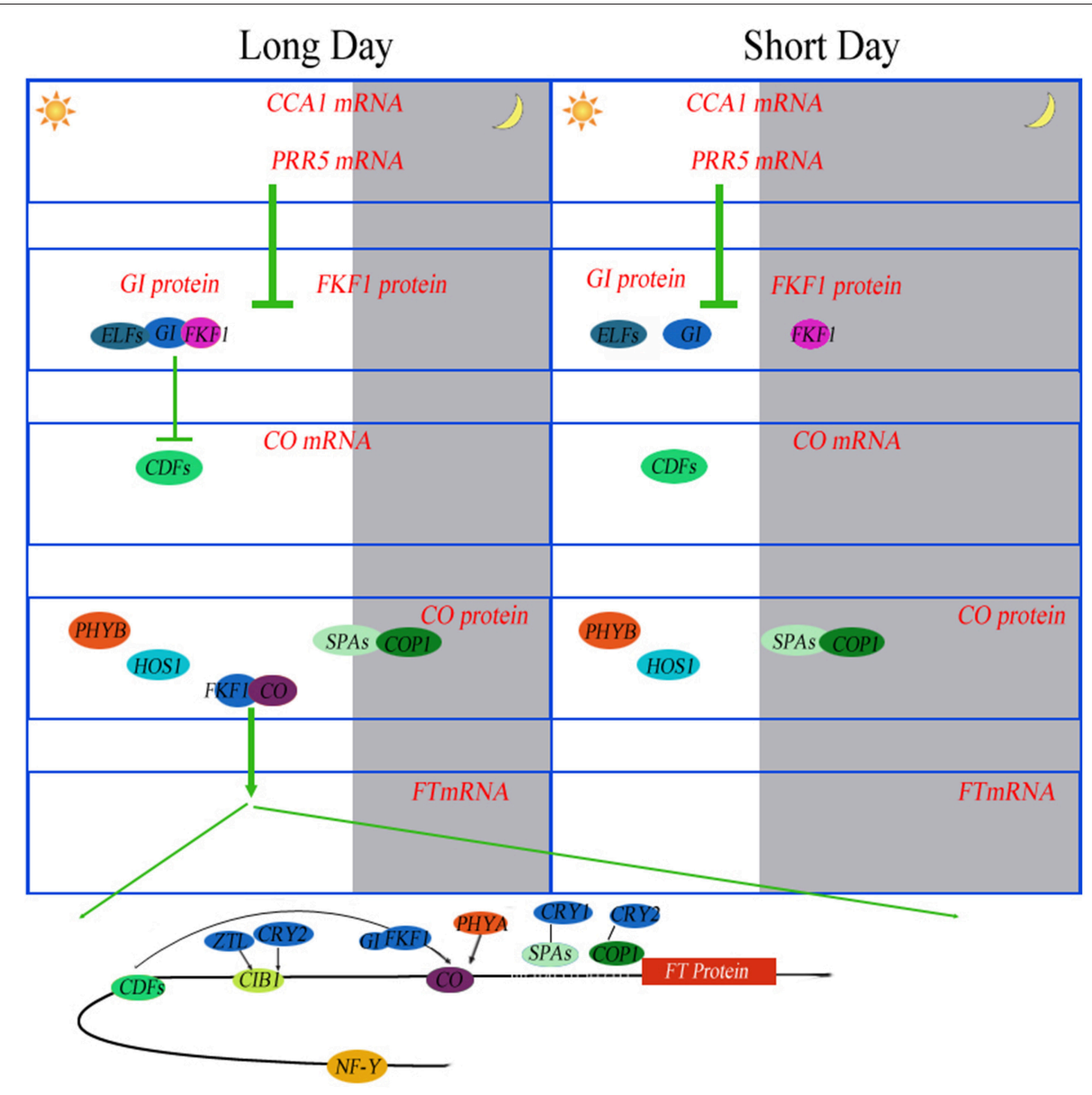

FIGURE 6 | Photoperiodic regulation of FT induction in Arabidopsis. Under long days (LD), the abundance of CCA1 transcripts oscillates throughout the day. CCA1 and its homolog LHY bind to the promoters of PRR5, FKF1 and GI to repress their expression in the morning. PRR5 also negatively controls the expression of CDF genes. Daily expression profiles of CDF1 are regulated by the FKF1-Gl complex. The same mechanism of degradation of CDFs by the FKF1-Gl complex is also exerted on the FT promoter. FKF1 physically interacts with CO protein to stabilize it. PHYA also stabilizes CO protein. Stabilized CO protein binds to the FT promoter to activate $\mathrm{FT}$ expression. NF-Y complex enhances the binding of $\mathrm{CO}$ protein to the FT promoter. CIB1 is activated by blue light absorbed by CRY2 and stabilized by blue light absorbed by ZTL. CIB1 directly activates the expression of FT in the afternoon. These proteins prevent flowering under unfavorable conditions, such as short days (SD). Under SD, the expression peaks of FKF1 and Gl do not coincide. In the absence of the FKF-Gl complex, CO expression is continuously suppressed by CDF proteins during the day.

flowering time through the photoperiodic pathway in maize (Ku et al., 2011). PSEUDO-RESPONSE REGULATOR 7 (PRR7), which is considered a "morning-expressed" gene, was isolated recently (Haydon et al., 2013). By inhibiting photosynthesis, the authors described that endogenous fluctuations in sugar levels supplied feedbacks at metabolic level to circadian oscillator via PRR7. In addition, $p p r 7$ mutants are insensitive to the oscillations of sucrose levels during circadian rhythms. Consequently, in Arabidopsis, robust circadian rhythms are stringently maintained by photosynthesis, demonstrating that the circadian clock is regulated by metabolism to a large extent (Haydon et al., 2013).

\section{CONCLUSIONS}

In this study, 5259 proteins were detected in maize leaves in the inbred lines HZ4 and H496. On the basis of MS/MS identification, 943 proteins were expressed differentially between HZ4 and H496, and those proteins were commonly shared by the newly expanded leaves from three- and six-leaf stages. Fourteen circadian associated proteins were also examined. The protein expression patterns of the inbred lines differed significantly even though the two lines share a similar genetic background. The proteomic changes in the maize leaf induced by LP treatment were highly function-specific, such as endoplasmic reticulum, splicesome, ribosome, glyoxylate, dicarboxylate metabolism, L-malate dehydrogenase activity, and RNA transport. The protein species differentially expressed between HZ4 and H496 were associated with photosynthesis including carbohydrate, chloroplast and ribosomal proteins at the three- or six-leaf stages in response to LP. To adapt to the outside environment, the phase of rhythms are adjusted in response to environmental signals, such light and external sugar supplement. The regulation patterns of light and circadian-associated protein under LP 
condition are discussed. The iron metabolism-related proteins and circadian-associated protein, such as K7U2L3, C0P8K7, and Q9ZR52, may mediate the photoperiodic pathway. The results offer novel insights into the influence of LP and provide additional information on the mechanism of circadian response in short-day plants at the proteomic level.

\section{AUTHOR CONTRIBUTIONS}

YC, LW, and LT conceived and designed the experiments. LW, LT, JZ, SW, PL, HZ, and HL Performed the experiments. LW and JZ Analyzed the data. YC and SW contributed reagents, materials and analysis tools. LW, YC, and LT wrote the manuscript.

\section{ACKNOWLEDGMENTS}

This work was supported by the National Natural Science Foundation of China (no. 31471503), the National Basic Research Program of China (973 Program, no. 2011CB111500), and the China Postdoctoral Science Foundation (no. 20100470993).

\section{REFERENCES}

Betran, F. J., Ribaut, J. M., Beck, D., and Gonzalez-de-Leo'n, D. (2003). Genetic diversity, specific combining ability, and heterosis in tropical maize under stress and nonstress environments. Crop Sci. 43, 797-806. doi: $10.2135 /$ cropsci2003.7970

Bindea, G., Galon, J., and Mlecnik, B. (2013). CluePedia Cytoscape plugin: pathway insights using integrated experimental and in silico data. Bioinformatics 29, 661-663. doi: 10.1093/bioinformatics/btt019

Bindea, G., Mlecnik, B., Hackl, H., Charoentong, P., Tosolini, M., Kirilovsky, A., et al. (2009). ClueGO: a Cytoscape plug-in to decipher functionally grouped gene ontology and pathway annotation networks. Bioinformatics 25, 1091-1093. doi: 10.1093/bioinformatics/btp101

Buckler, E. S., Holland, J. B., Bradbury, P. J., Acharya, C. B., Brown, P. J., Browne, C., et al. (2009). The genetic architecture of maize flowering time. Science 325, 714-718. doi: 10.1371/journal.pgen.1003790

Choudhary, M. K., Nomura, Y., Wang, L., Nakagami, H., and Somers, D. E. (2015). Quantitative circadian phosphoproteomic analysis of Arabidopsis reveals extensive clock control of key components in physiological, metabolic, and signaling pathways. Mol. Cell. Proteomics 14, 2243-2260. doi: 10.1074/mcp.M114.047183

Colasanti, J., and Coneva, V. (2009). Mechanisms of floral induction in grasses: something borrowed, something new. Plant Physiol. 149, 56-62. doi: 10.1104/pp.108.130500

Coles, N. D., McMullen, M. D., Balint-Kurti, P. J., Pratt, R. C., and Holland, J. B. (2010). Genetic control of photoperiod sensitivity in maize revealed by joint multiple population analysis. Genetics 184, 799-812. doi: 10.1534/genetics.109.110304

Covington, M. F., Maloof, J. N., Straume, M., Kay, S. A., and Harmer, S. L. (2008). Global transcriptome analysis reveals circadian regulation of key pathways in plant growth and development. Genome Biol. 9:R130. doi: 10.1186/gb-2008-98-r130

Dai, N., Schaffer, A., Petreikov, M., Shahak, Y., Giller, Y., Ratner, K., et al. (1999). Overexpression of Arabidopsis hexokinase in tomato plants inhibits growth, reduces photosynthesis, and induces rapid senescence. Plant Cell 11, 1253-1266.

Dai, Z. Y., Gao, J. W., An, K., Lee, J. M., Edwards, G. E., and An, G. (1996). Promoter elements controlling developmental and environmental regulation of a tobacco ribosomal protein gene L34. Plant Mol. Biol. 32, 1055-1065. doi: 10.1007/BF00041389

\section{SUPPLEMENTARY MATERIAL}

The Supplementary Material for this article can be found online at: http://journal.frontiersin.org/article/10.3389/fpls.2016. 00752

Figure S 1 | Accumulation content of sucrose (A), glucose(B) and $\mathrm{Fe}(\mathrm{C})$ between HZ4 and H496 in three- and six-leaf stages. Two-Way ANOVA followed by Student-Neuman-Keuls post-hoc test $(* * p<0.01, * p<0.05)$.

Table S 1 | All proteins were identified by MS/MS in 3-leaf stage and 6-leaf stage of HZ4 and H496 under LP condition.

Table S 2 | All peptides of identified proteins in three- and six-leaf stages of HZ4 and H496 under LP condition were identified by MS/MS.

Table S 3 | Differentially expressed protein in H496 compared to HZ4 in both two stages.

Table S 4 | Different expressed specially proteins in H496 compared to $\mathrm{HZ4}$ in 3-leaf stage.

Table S 5 | Different expressed specially protein in H496 compared to HZ4 in 6-leaf stage.

Table S 6 | Two-way analysis of variance of proteins differentially expressed at the three- and six-leaf stages in HZ4 and H496 grown underLP conditions. IL, inbred lines; DS, developmental stages.

Danilevskaya, O. N., Meng, X., Hou, Z. L., Ananiev, E. V., and Simmons, C. R. (2008). A genomic and expression compendium of the expanded PEBP gene family from maize. Plant Physiol. 146, 250-264. doi: 10.1104/pp.107. 109538

Devlin, P. F. (2002). Signs of the time: environmental input to the circadian clock. J. Exp. Bot. 53, 1535-1550. doi: 10.1093/jxb/erf024

Ducrocq, S., Giauffret, C., Madur, D., Combes, V., Dumas, F., Jouanne, S., et al. (2009). Fine mapping and haplotype structure analysis of a major flowering time quantitative trait locus on maize chromosome 10. Genetics 183, 1555-1563. doi: 10.1534/genetics.109.106922

Duncan, O., Taylor, N. L., Carrie, C., Eubel, H., Kubiszewski, J. S., Zhang, B. T., et al. (2011). Multiple lines of evidence localize signaling, morphology, and lipid biosynthesis machinery to the mitochondrial outer membrane of Arabidopsis. Plant Physiol. 157, 1093-1113. doi: 10.1104/pp.111.183160

Emerson, R. A. (1924). A genetic view of sex expression in the flowering plants. Science 59, 176-182. doi: 10.1126/science.59.1521.176

Fankhauser, C., and Staiger, D. (2002). Photoreceptors in Arabidopsis thaliana: light perception, signal transduction and entrainment of the endogenous clock. Planta 216, 1-16. doi: 10.1007/s00425-002-0831-4

Harmer, S. L., Hogenesch, J. B., Straume, M., Chang, H. S., Han, B., Zhu, T., et al. (2000). Orchestrated transcription of key pathways in Arabidopsis by the circadian clock. Science 290, 2110-2113. doi: 10.1126/science.290.5499.2110

Haydon, M. J., Mielczarek, O., Robertson, F. C., Hubbard, K. E., and Webb, A. A. (2013). Photosynthetic entrainment of the Arabidopsis circadian clock. Nature 502, 689-692. doi: 10.1038/nature12603

Hoenicka, H., Lautner, S., Klingberg, A., Koch, G., El-Sherif, F., Lehnhardt, D., et al. (2012). Influence of over-expression of the flowering promoting factor 1 gene (FPF1) from Arabidopsis on wood formation in hybrid poplar (Populus tremula L. $x$ P. tremuloides Michx.). Planta 235, 359-373. doi: 10.1007/s00425011-1507-8

Hoffman, D. E., Jonsson, P., Bylesjö, M., Trygg, J., Antti, H., Eriksson, M. E., et al. (2010). Changes in diurnal patterns within the Populus transcriptome and metabolome in response to photoperiod variation. Plant Cell Environ. 33, 1298-1313. doi: 10.1111/j.1365-3040.2010.02148.x

Hung, H. Y., Shannon, L. M., Tian, F., Bradbury, P. J., Chen, C., Flint-Garcia, S. A., et al. (2012). ZmCCT and the genetic basis of day-length adaptation underlying the postdomestication spread of maize. Proc. Natl. Acad. Sci. U.S.A. 109, 1913-1921. doi: 10.1073/pnas.1203189109

Kanehisa, M., and Goto, S. (2000). KEGG: kyoto encyclopedia of genes and genomes. Nucleic Acids Res. 28, 27-30. doi: 10.1093/nar/28.1.27 
Kim, Y., Lim, J., Yeom, M., Kim, H., Kim, J., Wang, L., et al. (2013). ELF4 regulates GIGANTEA chromatin access through subnuclear sequestration. Cell Rep. 3, 671-677. doi: 10.1016/j.celrep.2013.02.021

Knuesting, J., Riondet, C., Maria, C., Kruse, I., Bécuwe, N., Konig, N., et al. (2015). Arabidopsis Glutaredoxin S17 and its partner, the nuclear factor Y subunit C11/Negative Cofactor 2alpha, contribute to maintenance of the shoot apical meristem under long-day photoperiod. Plant Physiol. 167, 1643-1658. doi: 10.1104/pp.15.00049

Kovacs, L., Damkjaer, J., Kereïche, S., Ilioaia, C., Ruban, A. V., Boekema, E. J., et al. (2006). Lack of the light-harvesting complex CP24 affects the structure and function of the grana membranes of higher plant chloroplasts. Plant Cell 18, 3106-3120. doi: 10.1105/tpc.106.045641

Ku, L. X., Li, S. Y., Chen, X. A., Wu, L. C., Wang, X. T., and Chen, Y. H. (2011). Cloning and characterization of putative Hd6 ortholog associated with Zea mays L. photoperiod sensitivity. agricultural sciences in china. 10, 18-27. doi: 10.1016/S1671-2927(09)60286-8

Kumimoto, R. W., Zhang, Y., Siefers, N., and Holt, B. F. (2010). NF-YC3, NF-YC4 and NF-YC9 are required for CONSTANS-mediated, photoperiod-dependent flowering in Arabidopsis thaliana. Plant J. 63, 379-391. doi: 10.1111/j.1365313X.2010.04247.x

Lazakis, C. M., Coneva, V., and Colasanti, J. (2011). ZCN8 encodes a potential orthologue of Arabidopsis FT florigen that integrates both endogenous and photoperiod flowering signals in maize. J. Exp. Bot. 62, 4833-4842. doi: 10.1093/jxb/err129

Masuda, H., Suzuki, M., Morikawa, C. K., Kobayashi, T., Nakanishi, H., Takahashi, M., et al. (2008). Increase in iron and zinc concentrations in rice grains via the introduction of barley genes involved in phytosiderophore synthesis. Rice 1, 100-108. doi: 10.1007/s12284-008-9007-6

Matsubara, K., Yamanouchi, U., Wang, Z. X., Minobe, Y., Izawa, T., and Yano, M. (2008). Ehd2, a rice ortholog of the maize INDETERMINATE1 gene, promotes flowering by up-regulating Ehd1. Plant Physiol. 148, 1425-1435. doi: 10.1104/pp.108.125542

Matsuoka, Y., Vigouroux, Y., Goodman, M. M., Sanchez, G. J., Buckler, E., and Doebley, J. (2002). A single domestication for maize shown by multilocus microsatellite genotyping. Proc. Natl. Acad. Sci. U.S.A. 99, 6080-6084. doi: 10.1073/pnas.052125199

Metivier, J. V. A. (1979). The effect of long and short day length upon the growth of whole plants and the level of soluble proteins, sugars, and stevioside in leaves of Stevia rebaudiana Bert. J. Exp. Bot. 30, 1211-1222. doi: 10.1093/jxb/30.6.1211

Miao, H., Wei, J., Zhao, Y., Yan, H., Sun, B., Huang, J., et al. (2013). Glucose signalling positively regulates aliphatic glucosinolate biosynthesis. J. Exp. Bot. 64, 1097-1109. doi: 10.1093/jxb/ers399

Michael, T. P., and McClung, C. R. (2003). Enhancer trapping reveals widespread circadian clock transcriptional control in Arabidopsis. Plant Physiol. 132, 629-639. doi: 10.1104/pp.021006

Miller, T. A., Muslin, E. H., and Dorweiler, J. E. (2008). A maize CONSTANSlike gene, conzl, exhibits distinct diurnal expression patterns in varied photoperiods. Planta 227, 1377-1388. doi: 10.1007/s00425-008-0709-1

Missra, A., Ernest, B., Lohoff, T., Jia, Q. D., Satterlee, J., Ke, K., et al. (2015). The circadian clock modulates global daily cycles of mRNA ribosome loading. Plant Cell 27, 2582-2599. doi: 10.1105/tpc.15.00546

Möglich, A., Yang, X., Ayers, R. A., and Moffat, K. (2010). Structure and function of plant photoreceptors. Annu. Rev. Plant Biol. 61, 21-47. doi: 10.1146/annurevarplant-042809-112259

Müller, L. M., von Korff, M., and Davis, S. J. (2014). Connections between circadian clocks and carbon metabolism reveal species-specific effects on growth control. J. Exp. Bot. 65, 2915-2923. doi: 10.1093/jxb/eru117

Noh, Y. S., Bizzell, C. M., Noh, B., Schomburg, F. M., and Amasino, R. M. (2004). EARLY FLOWERING 5 acts as a floral repressor in Arabidopsis. Plant J. 38, 664-672. doi: 10.1111/j.1365-313X.2004.02072.x

Paijmans, J., Bosman, M., Wolde, P. R. T., and Lubensky, D. K. (2016). Discrete gene replication events drive coupling between the cell cycle and circadian clocks. Proc. Natl. Acad. Sci. U.S.A. 113, 4063-4068. doi: 10.1073/pnas.1507291113

Panda, S., Antoch, M. P., Miller, B. H., Su, A. I., Schook, A. B., Straume, M., et al. (2002). Coordinated transcription of key pathways in the mouse by the circadian clock. Cell 109, 307-320. doi: 10.1016/S0092-8674(02)00722-5
Papasaikas, P., Tejedor, J. R., Vigevani, L., and Valcárcel, J. (2015). Functional splicing network reveals extensive regulatory potential of the core spliceosomal machinery. Mol. Cell 57, 7-22. doi: 10.1016/j.molcel.2014. 10.030

Park, M.-J., Seo, P. J., and Park, C. M. (2012). CCA1 alternative splicing as a way of linking the circadian clock to temperature response in Arabidopsis. Plant Signal. Behav. 7, 1194-1196. doi: 10.4161/psb.21300

Paul, L. K., and Khurana, J. P. (2008). Phytochrome-mediated light signaling in plants: emerging trends. Physiol. Mol. Biol. Plants 14, 9-22. doi: 10.1007/s12298-008-0002-6

Piperno, D. R., Ranere, A. J., Holst, I., Iriarte, J., and Dickau, R. (2009). Starch grain and phytolith evidence for early ninth millennium B.P. maize from the Central Balsas River Valley, Mexico. Proc. Natl. Acad. Sci. U.S.A. 106, 5019-5024. doi: 10.1073/pnas.0812525106

Ravet, K., Touraine, B., Boucherez, J., Briat, J. F., Gaymard, F., and Cellier, F. (2009). Ferritins control interaction between iron homeostasis and oxidative stress in Arabidopsis. Plant J. 57, 400-412. doi: 10.1111/j.1365313X.2008.03698.x

Reinbothe, C., Pollmann, S., and Reinbothe, S. (2010). Singlet oxygen signaling links photosynthesis to translation and plant growth. Trends Plant Sci. 15, 499-506. doi: 10.1016/j.tplants.2010.05.011

Salome, P. A., Oliva, M.,Weigel, D., and Kramer, U. (2013). Circadian clock adjustment to plant iron status depends on chloroplast and phytochrome function. $E M B O$ J. 32, 511-523. doi: 10.1038/emboj.2012.330

Sandberg, A., Lindell, G., Källström, B. N., Branca, R. M., Danielsson, K. G., Dahlberg, M., et al. (2012). Tumor proteomics by multivariate analysis on individual pathway data for characterization of vulvar cancer phenotypes. Mol. Cell. Proteomics 11:M112.016998. doi: 10.1074/mcp.M112. 016998

Staiger, D., and Köster, T. (2011). Spotlight on post-transcriptional control in the circadian system. Cell. Mol. Life Sci. 68, 71-83. doi: 10.1007/s00018-0100513-5

Thalor, S. K., Berberich, T., Lee, S. S., Yang, S. H., Zhu, X., Imai, R., et al. (2012). Deregulation of sucrose controlled translation of a bZIP-Type transcription factor results in sucrose accumulation in leaves. PLOS ONE 7:e33111. doi: 10.1371/journal.pone.0033111

Turck, F., Zilbermann, F., Kozma, S. C., Thomas, G., and Nagy, F. (2004). Phytohormones participate in an S6 kinase signal transduction pathway in Arabidopsis. Plant Physiol. 134, 1527-1535. doi: 10.1104/pp.103.035873

Turkina, M. V., Årstrand, H., and Vener, A. V. (2011). Differential phosphorylation of ribosomal proteins in Arabidopsis thaliana plants during day and night. PLoS ONE 6:e29307. doi: 10.1371/journal.pone.0029307

Urbanczyk-Wochniak, E., Baxter, C., Kolbe, A., Kopka, J., Sweetlove, L. J., and Fernie, A. R. (2005). Profiling of diurnal patterns of metabolite and transcript abundance in potato (Solanum tuberosum) leaves. Planta 221, 891-903. doi: 10.1007/s00425-005-1483-y

van Heerwaarden, J. V., Doebley, J., Briggs, W. H., Glaubitz, J. C., Goodman, M. M., de Jesus Sanchez Gonzalez, J., et al. (2011). Genetic signals of origin, spread, and introgression in a large sample of maize landraces. Proc. Natl. Acad. Sci. U.S.A. 108, 1088-1092. doi: 10.1073/pnas.1013011108

Victor, K. J., Fennell, A. Y., and Grimplet, J. (2010). Proteomic analysis of shoot tissue during photoperiod induced growth cessation in V. riparia Michx. grapevines. Proteome Sci. 8:44. doi: 10.1186/1477-5956-8-44

Wang, N., Ku, L. X., Chen, Y. H., and Wang, W. (2015). Comparative proteomic analysis of leaves between photoperiod-sensitive and photoperiod-insensitive maize inbred seedlings under long day treatments. Acta Physiol. Plant. 37:1705. doi: $10.1007 /$ s11738-014-1705-7

Williams, A. J., Werner-Fraczek, J., Chang, I. F., and Bailey-Serres, J. (2003). Regulated phosphorylation of $40 \mathrm{~S}$ ribosomal protein S6 in root tips of maize. Plant Physiol. 132, 2086-2097. doi: 10.1104/pp.103.022749

Wisniewski, J. R., Zougman, A., Nagaraj, N., and Mann, M. (2009). Universal sample preparation method for proteome analysis. Nat. Methods 6, 359-362. doi: $10.1038 /$ nmeth.1322

Wu, L. C., Wang,T. G., Ku, L. X., Huang, Q. C., Sun, Z. H., Xia, Z. L., et al. (2008). Determination of the photoperiod-sensitive inductive phase in maize with leaf numbers and morphologies of stem apical meristem. Agr. Sci. China 7, 554-560. doi: 10.1016/S1671-2927(08)60052-8 
Yang, L. T., Qi, Y. P., Lu, Y. B., Guo, P., Sang, W., Feng, H., et al. (2013). iTRAQ protein profile analysis of Citrus sinensis roots in response to longterm boron-deficiency. J. Proteomics 93, 179-206. doi: 10.1016/j.jprot.2013. 04.025

Yang, Q., Li, Z., Li, W., Ku, L., Wang, C., Ye, J., et al. (2013). CACTAlike transposable element in ZmCCT attenuated photoperiod sensitivity and accelerated the postdomestication spread of maize. Proc. Natl. Acad. Sci. U.S.A. 110, 16969-16974. doi: 10.1073/pnas.1310949110

Ye, J., Fang, L., Zheng, H., Zhang, Y., Chen, J., Zhang, Z., et al. (2006). WEGO: a web tool for plotting GO annotations. Nucleic Acids Res. 34, W293-W297. doi: 10.1093/nar/gkl031
Conflict of Interest Statement: The authors declare that the research was conducted in the absence of any commercial or financial relationships that could be construed as a potential conflict of interest.

Copyright $\odot 2016$ Wu, Tian, Wang, Zhang, Liu, Tian, Zhang, Liu and Chen. This is an open-access article distributed under the terms of the Creative Commons Attribution License (CC BY). The use, distribution or reproduction in other forums is permitted, provided the original author(s) or licensor are credited and that the original publication in this journal is cited, in accordance with accepted academic practice. No use, distribution or reproduction is permitted which does not comply with these terms. 